\title{
Causal attribution and the analysis of literary characters: A. C. Bradley's study of lago and Othello
}

\author{
ENRIQUE CÁMARA ARENAS
}

\begin{abstract}
A. C. Bradley's approach to character-construal in Shakespearean Tragedy (1904) has often been regarded as a good example of the humanizing approach to literary characters. His lectures on Iago, Othello or Macbeth have been criticized by other scholars for a number of reasons, but particularly for using premises and facts in his argumentation which are not found in the plays. Bradley's task is in many senses an example of person perception, which he performs without alluding to any social psychological theories or methods. In the present article I revise Bradley's reasoning in the light of Kelley's Covariance Theory of Causal Attribution, in an attempt both to re-evaluate Bradley's procedures and, especially, to determine ways in which social psychology might provide literary critics with valuable tools and insights.
\end{abstract}

\section{Introduction: Bradley and the humanizing approach to literary characters}

In 1904, the Oxford professor A. C. Bradley published in book form a series of lectures on Shakespeare's tragedies. That book has long been considered a classic by those who study the works of the playwright. It has also been, so to say, classically criticized at different times, so much so that F. R. Leavis even complained in 1952 that disrespect for Bradley was no longer fashionable (Wain 1971: 124). Some forty years after the publication of Bradley's Shakesperian Tragedies (1904), L. C. Knights, in his Explorations (1946) did not hesitate to count the professor among the 'bad critics', who were characterized generally as follows:

The main difference between good and bad critics is that the good critic points to something that is actually contained in the work of art, whereas the bad critic 
points away from the work in question; he introduces extraneous elements into his appreciation - smudges the canvas with his own paint. (1963:7)

Most of the extraneous elements the professor introduces in his discourse have to do with the so-called humanizing approach to fictional characters, of which Bradley is actually one of the best representatives (Culpeper 2001: 6). Later scholars have shared the belief that most readers make sense of literary characters by resorting to the same processes they generally use in making sense of real people (Toolan 1988: 92; Emmott 1997: 58; Culpeper 2001: 10). As such, the argument is presented as an unverified supposition. But, beyond this, the humanizing approach to fictional characters can be considered one of the corollaries of a well established and carefully construed theory of the literary phenomenon. It is one which is connected to highly respected intuitions like Walton's 'game of makebelieve', Coleridge's 'willing suspension of disbelief' or even Aristotle's notion of art as imitation.

The humanizing approach necessarily implies the consideration of elements which are not in the text, just as in making sense of real people deciding what they are like and why they behave the way they do - we bring into play expectations, stereotypes, implicit theories of personality and other cognitive structures which exist outside of the directly observable or textual data. Today, in the wake of the cognitive shift, many are convinced that reading and interpreting is, in some way or another, 'smudging the canvas with our own paint'. Although rather than smudging, which implies obscuring the view of the original painting with one's blots, we would speak of bringing the painting to completion by incorporating our own creative brushstrokes.

Cognitive researchers have also shown that the application of cognitive extra-textual structures is actually a principled process. Our making sense of texts and characters does certainly incorporate subjective and personal elements - a bit of subjective smudging if you want; but subjectivity itself, far from being whimsical or chaotic, works according to universal and objectifiable principles. This apparently paradoxical situation -the notion of objectivity in subjectivity- translates, in relation to criticism of Bradley's analyses, into another seeming contradiction: the same critics who have considered them a failure, have lamented - and therefore acknowledged the fact that Bradley's analyses have been extraordinarily influential and, therefore, a rhetorical success. I hope to demonstrate that this success is due to the fact that, however subjective, enthusiastically inventive and personal it may be, Bradley's construction of Shakespeare's characters is strictly respectful towards the universal principles that govern what psychologists call causal attribution. I argue that a reconsideration of Brad- 
ley's procedures in the light of social psychology will help us bring the humanizing approach onto a higher level of methodological sensitivity. I will show that Bradley intuitively followed the kind of argumentative principles that were later made explicit by social psychologists like $\mathrm{H}$. $\mathrm{H}$. Kelley and his Covariance Theory of Causal Attribution (CTCA).

\section{Kelley's Covariance Theory of Causal Attribution}

Linguists and literary scholars might not be familiar with Kelley's covariation model unless they are particularly interested in social cognition and its role in verbal communication. Therefore I will offer a very brief summary of CTCA in this section. Kelley's own writing on the subject (especially 1967 and 1973) is accessible enough, although there are good and friendlier introductions to the model in most handbooks of Social Psychology (Schneider 1979; Hewstone 1996; Augoustinos 2006). Culpeper's treatment of the theory in Language and Characterization (2001: 126-129) is an excellent introduction for linguistic and literary researchers. Although in Culpeper's sample analysis (2001: 265-286), causal attribution theories do not play a central role, constituting one among many other analyzing tools, he certainly concedes much theoretical importance to CTCA and offers an insightful integration of Kelley's theory with another landmark in casual attribution studies: the Theory of Correspondent Inferences formulated by Jones and Davis (1965).

In order to explain Kelley's theory very briefly, even at the risk of oversimplifying it, I will illustrate it with a canonical example. Imagine that a friend of yours has failed an exam. According to Kelley, you have only three possible ways of answering the question 'why has he failed?': (i) you could make a causal attribution to the stimulus: he failed because the exam - which is the stimulus - was very difficult, unfair, imprecise, etc.; or (ii) an attribution to your friend's circumstances: the exam was fine, but he had a very bad cold, he could not sleep the night before because of all the coughing and congestion, his head ached terribly, he was feverish, etc. Finally, you could make (iii) an attribution to the subject: your friend is simply not too clever, and/or he is quite lazy, has little sense of pragmatism, etc. Beyond this triple choice, our minds can only conceive combinations of them; therefore, this tripartite pattern reflects human cognitive ability to explain the behavior of real people.

As long as we are ready to accept that readers tend to treat fictional characters as if they were real, the answer to Bradley's question 'why did Iago act that way?' must necessarily fit into these general categories or one of their combinations: Iago either responded to a certain external stimulus 
just as most people would have done, and/or he was living, at the time of acting, through a set of circumstances that altered his usual way of acting and transitorily influenced his behavior, and/or he acted the way he did because he was the way he was. This is already some contribution to literary characterization analysis. Furthermore, CTCA offers a description of the analytical process by which a human mind chooses among the three general causes.

We can only derive confidence to support any of these hypothetical explanations by monitoring and considering the relevance of three information fields: going back to the exam failure, for example, we take into account (a) a rough consideration of the average percentage of students who failed the exam (i.e. consensus); (b) whether your friend usually performs differently when his circumstances are different (i.e. consistency); and (c) whatever you know about your friend's failures or successes in other kinds of tests and problem solving situations (i.e. distinctiveness). The basic reasoning related to each of the information fields can be easily summarized as follows:

Concerning a Stimulus $\mathrm{S}$, a Reaction $\mathrm{R}$, and an observed individual $\mathrm{P}$ Situation: $\mathrm{P}$ has reacted with $\mathrm{R}$ to $\mathrm{S}$

Consensus: (high) Evervbodv/ (low) Nobody has reacted with $\mathrm{R}$ to $\mathrm{S}$ Consistency: P (high) alwavs/ (low) only this time has reacted with $\mathrm{R}$ to $\mathrm{S}$

Distinctiveness: P reacts with R (high) only to $S$ / (low) to many other stimuli

Observers are likely to point to stimulus as the cause of failure if a high percentage of the students also failed the same exam: high consensus. They can propose circumstances as the cause of failure only if they can prove that in the past under more benign circumstances the result has been different: low consistency. And they will tend to consider the subject as the cause of failure if they consider this failure as yet another example of his often proved inability to succeed in intellectually demanding tasks: low distinctiveness.

The rhetorical properties of this system are derived from the fact that the three arguments are interrelated in a way that they help reinforce (or undermine) any of the three attributions. The perfect reinforcement of one cause happens when convincing evidence is added for discarding the other two. For example, the fact that $95 \%$ of the students have failed the exam might be enough to support the hypothesis that the exam was too difficult or inadequate. But this hypothesis will be strengthened if we prove that nothing in the subject's circumstances can explain the failure. And the hypothesis will be further reinforced if we add that the subject has often proved to be exceptionally good at everything intellectual and perfectly re- 
sponsible concerning his duties, therefore discarding stupidity and laziness, or any other character flaw, as possible causes.

high consensus + high consistency + high distinctiveness $=$ attribution to stimulus

In the same way, providing evidence for discarding stimulus and circumstances reinforces attribution to subject, while providing evidence for discarding stimulus and subject as the cause reinforces attribution to circumstances.

low consensus + low consistency + high distinctiveness $=$ attr. to circumstance

low consensus + high consistency + low distinctiveness $=$ attr. to subject

What I am describing here is a mode or reasoning which assists the process of validating or undermining beliefs. It would be completely against common sense to suggest that in order to decide whether an exam is difficult we must wait to see how many students manage to pass it, and then consider their circumstances and their personality profiles, and proceed carefully to analyze covariance.

The notion that a certain exam is difficult, or certain circumstances extenuating, or certain individuals intelligent usually spring to mind in the form of simpler intuitions, which have more to do with the projection of personal experience than with covariant analysis: ' $I$ might fail this exam' (so, it is difficult), ' $I$ would hardly manage to study under such circumstances' (so, they are extenuating), 'I might not have been able to provide such an intelligent answer' (so, this person is intelligent), etc. This is, by no means, a criticism of Kelley's model, but rather a warning against trying to use CTCA for purposes for which it has not been designed. In the next section, I will try to shed some light upon such a danger.

Even when using CTCA strictly for developing analytic and properly articulated answers to the question 'why does this person/character behave this way?', one should not be tempted to consider Kelley's theory as method for determining objective truth. The reason why a character or a real person behaves in one way or another will always remain a topic for debate; being as it is a matter of interpretation, it is inherently impossible to abandon here the realm of speculation and subjectivity. This is not a criticism of Kelley's model, either; on the contrary, Kelley's remarkable achievement consists in bringing to our awareness the objective principles that guide such subjective (speculative) reasoning; a typically cognitive accomplishment, by the way. 


\section{Taking CTCA for what it is: Cause-attribution vs. trait-attribution}

Construing a character implies, at least, providing an answer to two basic questions: (1) "What is the character like?", and (2) "Why does the character behave the way she does? The first question initiates a process of trait-attribution; the second calls for a process of causal-attribution. The way I understand them, both processes are interconnected at different points in very subtle ways, especially in the case of so-called internal (causal) attribution, when one concludes that the character behaves the way she does, simply because she is the way she is. Still, interconnection should not lead to confusion. ${ }^{2}$

Strictly speaking, Kelley does not deal with the attribution of personality traits to people or characters, but with the attribution of causes to events - question (2) above. So, however revealing, CTCA illuminates specific regions of personality construing and characterization, leaving others in the shadows. It is behavior interpreted as selfish that leads to the attribution of the trait 'selfish', and there is nothing in CTCA to help us explain why a certain behavior is categorized as selfish and not as something else.

Certainly, with Kelley's guidance we could analyze a certain behavior viewed in terms of consensus, consistency and distinctiveness - and conclude that neither stimuli nor circumstance can explain this specific behavior satisfactorily. In that case, CTCA would lead us to assume that there is something in the subject's personality - a trait or a disposition - that causes that particular way of acting. Kelley's model, being a causal-attribution model, can only characterize such a trait or disposition by referring to the specific non-generalized ${ }^{3}$ behavior it has caused. An observer that has followed the process to this point can only indentify such a disposition as, for instance, selfishness after applying behavior categorization processes which constitute a set of cognitive procedures different from CTCA reasoning. The human mind can attribute traits to people or characters through several cognitive processes. Sometimes we do it intuitively, relying on what we call first impressions, snap judgments (Schneider, 39, 252), or on-line judgments (Hastie, 1), etc. Sometimes trait-attribution is the result of a more analytic process, which may be rooted into an implicit theory of personality (Hogg, 46; Schneider, 161), or an agreed theory. Perhaps the most obvious example of a careful and methodical process of trait attribution is the personality test; each school or perspective has its own way of processing data in order to attribute traits to the observed subject and predict behavior (Totton 2001).

Although trait-attribution and causal-attribution should never be confused, there are situations in which an interplay between both processes 
happens quite naturally. ${ }^{4}$ One such situation has already been described in the previous paragraph: first we decide that a behavior has been caused by a personal disposition - CTCA reasoning; then we categorize that disposition as selfishness - behavior categorization process. An inverted variant of this sequence also seems commonsensical: first we attribute a trait of selfishness after observing behavior; then we reconsider whether such trait can be either confirmed or explained away ${ }^{5}$ after taking into account the absence or presence of mitigating factors such as powerful stimuli or extenuating circumstances.

Our scientific tendency to classify, separate, and organize phenomena into sequences should not prevent us from considering the possibility that both processes - trait attribution and cause-attribution - could run in parallel, somehow controlling each other's outcomes. Since I intend to keep my attention within the limits of Bradley's intuitive application of CTCA principles, any attempt at describing such an intricate process would lead us away from the goals of this paper. Although separating trait-attribution from cause-attribution might well constitute an artificial procedure, having drawn a line between them will ensure, I think, the theoretical asepsis necessary to carry out my purposes here. It is in CTCA, after all, where a rhetorical potential resides which can be used in character analysis.

\section{Bradley's argumentation viewed from a CTCA perspective}

\subsection{Attribution to subject and character foregrounding}

Bradley's emphasis on the importance of providing an answer to the question "Why did [Iago] act as we see him acting in the play" is an essential element in his construing strategy, and one that takes us into the domain of causal attribution. There seems to be a natural connection between the grandeur and memorability of a character and the reader's perplexity in providing an answer to the question why. If someone is marked with a red-hot iron, no observer will ever wonder why he cries out. At a dance, no-one will ask why a young woman is dancing. In such situations, neither crying nor dancing can tell us much about the subjects. But when we are faced with low consensus - if the subject refuses to cry or to dance in our examples - that is, when we feel that the subject is acting as nobody else would, or when we detect some kind of disproportion or inappropriateness in someone's responses, we turn our eyes to the subject's personality. Then our necessity of understanding why coincides with a necessity of understanding character. 
At the beginning of his sixth lecture, Bradley refutes two interpretations of Iago which, in spite of being popularly accepted, he considers wrong. The first rejected version actually contains a bundle of three hypotheses:

Their Iago is simply a man who has been slighted and revenges himself; or a husband who believes he has been wronged, and will make his enemy suffer a jealousy worse than his own; or an ambitious man determined to ruin his successful rival - one of these or a combination of these, endowed with unusual ability and cruelty. (Bradley 209)

The reason why Bradley discards these versions can be expressed in CTCA terms. The first two explanations in the bundle have the appearance of attributions to stimuli. In the first, having been slighted is a stimulus to which Iago responds by revenging. In the second, the stimulus is whatever raises Iago's suspicion that he has been cheated on.

The pure attribution to stimulus requires the assumptions of high distinctiveness, high consistency and high consensus. If being slighted counts as the stimulus, and malevolently plotting as the behavior, the assumptions in Iago's case would be the following: (1) that Iago would only behave like this when slighted in this particular way; (2) that he would always behave like this when slighted in this particular way; and (3) that most people would behave like this when slighted in this particular way. The analysis of the second version would be the same, replacing being cheated on for the stimulus. ${ }^{6}$ Any disagreement with any of the three assumptions will immediately challenge the attribution to stimulus.

Notice, however, that admitting the presence of a stimulus does not necessarily mean that the stimulus is the main cause of behavior. We may freely admit the presence of both stimuli, being slighted and suspicion of infidelity, and still consider that they do not explain behavior to the full. In fact, in answering the question 'why does Iago behave this way?', the statement: 'because he has been slighted' or 'because he suspects infidelity' are, according to Bradley, too simple and insufficient. As he says: "they convert [Shakespeare's] Iago into an ordinary villain" (208-209), and "they reduce Shakespeare to common place" (208).

This perception of ordinariness is connected to the assumption of high consensus, which states that most people would carry out some kind of aggressive strategy when being seriously slighted or cheated on. Such understanding of the events points away from the character, who behaves here just like the next man, mechanically propelled by blinding external forces. So understood, Iago's character is devoid of mystery and grandeur. In framing Iago within a plot of stimulus-reaction, affront-vengeance, we are making it impossible for us to enjoy the particular and idiosyncratic greatness of this character; whereas properly understood - Bradley claims (208) 
- Iago's literary stature is comparable to Hamlet's, Falstaff's and Cleopatra's. It is the attribution to stimulus which turns Iago into an ordinary villain. For his part, as we will see, Bradley defends an attribution to subject as the cause of Iago's plotting, and explains it by alluding to a sophisticated set of psychological dispositions, ${ }^{7}$ which include a sense of superiority and intellectual pride.

The assumptions implied in any attribution to subject are low consensus, high consistency, and low distinctiveness: (1) Iago behaves as very few people would in relation to a stimulus; (2) he would always respond this way to such a stimulus; and (3) he would behave like this when faced with a wide variety of stimuli different from this one. Assumptions (2) and (3) have to do with the regularity and predictability of Iago's behavior, but it is the assumption related to consensus that is the one that either makes a character stand out from the rest, or reduces them to commonality.

If, in the case of Iago, the professor refuses an attribution to stimuli in favour of an attribution to subject, in dealing with Othello his argument goes the other way around. In the fifth lecture, Bradley proposes an attribution to stimulus to explain the hero's behavior, and he does so in order to counter the popular view that Othello acts the way he acts because he is - attribution to subject - characteristically jealous:

Now I repeat that any man situated as Othello was would have been disturbed by Iago's communications, and I add that many men would have been made wildly jealous. [ . . ] Othello, I must maintain, does not show jealousy. His confidence is shaken, he is confused and deeply troubled, he feels even horror but he is not yet jealous in the proper sense of the word. (194)

The emphasis on any is Bradley's, and it reflects his intuition that high consensus is the best ally for his argument. Of course, Othello is now the one who has been, so to say, degraded to the condition of the common man. $\mathrm{He}$ is no longer the memorable epitome of jealousy, but merely a man as jealous as the next under such circumstances and influenced by such stimuli. ${ }^{8}$ F. R. Leavis reproduced the quote above in an article written in defense of good criticism against "triumphal sentimental perversity" (126), and intended to discredit Bradley's reading of the play. ... The latter, defended with "comical solemnity", Leavis considered "completely wrong-headed - grossly and palpably false" (Wain 121). Not surprisingly, Leavis feels the need to raise Othello above that level of commonality where Bradley sinks him, and to put Iago in its place:

Othello is the chief personage - the chief personage in such a sense that the tragedy may fairly be said to be Othello's character in action. Iago is subordinate and merely ancillary. He is not much more than a necessary piece of dramatic mechanism. (Wain 125) 
It is matter of foregrounding that we are dealing with here. Depending on how you view the causal relations within the plot, either Iago or Othello becomes a hero or a puppet. Fortunately, I do not need to take part in this forgotten disagreement. The way I see it, what comes up victorious is precisely one of the main arguments derived from attribution theories, namely, that when we attribute the cause of behavior to external factors, personality goes to the background, and with it, I might add, the interest and grandeur of characters; and when we encounter difficulties in explaining behavior as caused by external factors, our attention is, or tends to be, directed to the character's personality, which jumps to the foreground and captivates our interest. These interpretative decisions, as I will discuss later, eventually affect the understanding of structural, esthetic and semantic aspects of the play as a whole.

\subsection{From cause attribution to trait attribution}

His remark that "Iago's plot is Iago's character in action" (179) proves that according to Bradley it is an attribution to subject that we need in order to understand Iago's behavior, and actually any of Shakespeare's plays. ${ }^{9}$ But the third version rejected by Bradley - "an ambitious man determined to ruin his successful rival" - may already constitute an attribution to subject. As such it would imply the following assumptions: (1) that Iago responds to professional rivalry in a way that very few people would (low consensus); (2) that whenever faced with professional rivalry he would respond in a similar way again and again whatever his circumstances (high consistency); and (3) that he would behave in a similar way when faced with diverse stimuli, different from professional frustration (low distinctiveness). This is as far as we can go with CTCA: Iago does not respond to anything external, but to internal idiosyncratic forces. This reasoning rules out the possibility of considering lago a common man; he might be considered the very incarnation of pure ambition, grand and memorable as such. But this is not enough for Bradley.

Deciding that Iago's character can be categorized as ambitious is something that observers do, as I have already pointed out, by resorting to an implicit theory of personality. Bradley, relying on his own theory of personality, proposes a disposition far more complex and sophisticated, and rather unexpected and original in my opinion. But he still uses implicit CTCA reasoning in order to challenge the view that Iago is ambitious:

Certainly he is devoted to himself; but if he were an eagerly ambitious man, surely we should see much more positive signs of this ambition; and surely too, with his great powers, he would already have risen high instead of being a mere ensign, short of money, and playing Captain Rook to Roderigo's Mr. Pigeon. (220) 
Bradley offers two arguments to rebut ambition as the possible cause of Iago's ill doings. The second one - "he would already have risen" - has nothing to do with CTCA and is, in my opinion, the weaker of the two. This argument is based on the belief that all ambitious men will get on in the world as long as they have certain qualities. This view underestimates the effect of chance or external circumstances that might reasonably hinder any ambitious and capable man's promotion.

I cannot claim that the first of Bradley's arguments - “... we should see more positive signs of this ambition" - is unquestionable, but it is certainly connected to CTCA. Accepting ambition as the cause of Iago's behavior implies, as I have already mentioned, assuming low distinctiveness, i.e. the belief that Iago would show his ambition in responding to a wide variety of stimuli. Since, according to Bradley, nothing of this is reported or contained in the play - there are not enough 'signs of ambition' - a causal-attribution to Iago's supposedly ambitious disposition is discarded. This view is not safe from criticism, of course, and other observers might well complain that there are ambitious behaviors in Iago which Bradley does not consider indicative of ambition. I will discuss the problem of relativity in a later section of this paper.

Bradley's causal interpretation of Iago's behavior is an exemplar of implicit CTCA reasoning, he alludes to a set of dispositions convincingly connected to the kind of plotting carried out by Iago; he establishes a reasonable stimulus; and he minimizes the role of circumstances.

Bradley construes Iago's dispositions and character by interpreting some cues that he finds in the text and by completing them with his own implicit theory of personality. He does not need CTCA for this, but his construction is orderly and commonsensical. First, he points to one of Iago's cardinal beliefs. The premise that one's philosophy of life influences one's actions and reactions is, I would say, readily acceptable. Here, according to Bradley, is Iago's creed: "absolute egoism is the only rational and proper attitude" (219). Anyone who goes by such a philosophy will naturally behave egoistically and, besides, will feel quite proud and satisfied in doing so. Again, Bradley's argument is weak in one sense: if you deny that this is really Iago's creed, and consider it an overemphasized aspect, extraneously incorporated by Bradley, the whole explanation falls down. But if you give credit to Bradley's hypothesis, then Iago is illuminated and we feel that we have learned something that makes Iago more understandable and the play more enjoyable. In this second sense, Bradley's argument is strong.

Notice that not just any creed would have had the same explicative power. From this basic creed Bradley manages to derive a whole set of dispositions which seem consistent both with that particular philosophy 
and with the tendency to plot and scheme against others. ${ }^{10}$ Bradley summarizes Iago's relevant dispositions as follows:

the keen sense of superiority, the contempt for others, the sensitiveness to everything which wounds these feelings, the spite against goodness in men as a thing not only stupid but, both in its nature and by its success, contrary to Iago's nature and irritating to his pride. (227)

These dispositions are at the bottom of Iago's behavior. For Bradley they are bound to emerge in response to a wide variety of stimuli - low distinctiveness. Actually, Iago would seize any chance to give "satisfaction to his sense of power and superiority", any opportunity to exert his abilities (228), to confirm his own value and values, and to prove to himself that he is a man above the rest. The whole construction will collapse if we attack any of its subjective, speculative premises. But if we accept them, then this Iago really makes sense.

Bradley's reasoning gravitates, as we have just seen, around the notion of low distinctiveness; there is, in the professor's discourse, another argument which points to high consistency with surprising directness: "At any time he would have enjoyed befooling and tormenting Othello" (228, emphasis in original). Such a premise, being absolutely unauthorized by the text and so freely provided by Bradley's guesswork, is bound to irritate more than one critic. But, within Bradley's socio-psychological frame it exerts a valuable persuasive power, implying that Iago would have plotted to befool and torment Othello, or anybody, whatever the circumstances. It is a new invitation to turn our eyes to the subject, a new defense of Iago's literary magnificence.

Here we might question Bradley using his own reasoning. If he did not consider Iago ambitious because "we should see more positive signs of this ambition", why should we consider him a psychopathic schemer if in many years of serving Othello he has only betrayed him this particular time? In CTCA terms, if consistency is high (Iago schemes anytime, anywhere) and distinctiveness is low (he schemes whatever the stimuli), why is it that he only does it once? Bradley has an answer for this; and the fact that this answer follows immediately after his defense of high consistency should not surprise us:

Othello's goodness, and his own dependence on Othello, must have been a perpetual annoyance to him [Iago]. At any time he would have enjoyed befooling and tormenting Othello. Under ordinary circumstances he was restrained by selfinterest, in some slight degree perhaps by the faint pulsations of conscience and humanity (228).

Here, Bradley is admitting that something in Iago's circumstances has changed. In CTCA terms there is a possible contradiction here: if Iago re- 
acts to unordinary circumstances, as the quote suggests, then we are challenging the attribution to subject. But, as I have mentioned before, attributing the cause to the subject's dispositions does not mean that there is no stimulus at work. And Bradley, in one single movement, both acknowledges its presence and minimizes its causal impact: "disappointment at the loss of the lieutenancy supplied the touch of lively resentment that was required" (228). There is a stimulus, but it is merely a "touch" that does not fully explain the disproportioned magnitude of Iago's behavior.

Bradley's argument is strictly built along the logical lines that govern causal attribution; he emphasizes low distinctiveness and high consistency and low consensus, and challenges the distinctiveness, consistency and consensus of the refuted versions. That is the general description of his persuasive method. Of course, this does not defend him from those who accuse him of capriciously creating his own Iago, but it helps to convey consistency and a valuable persuasive power to his version which strongly affects those who accept his game from the start. His Iago, a psychopathic schemer who finds pleasure in torturing as an expression of his own selfcomplacency, and who lacks any sense of humane feeling, is endowed with fullness and intelligibility. He is ready to be enjoyed by the audience.

Not all that has been required is CTCA reasoning; implicit theories of personality and causality have also played an essential role in his perception of Shakespeare's villain. Truly enough, these elements conform to what Knights rejected as the critic's "own paint" smudging the canvas. But this smudging is neither careless, nor entirely anarchic.

\subsection{Causally interconnected constructs of characters}

Bradley's argumentation shows that when dealing with fictional environments it may well happen that the way we construe some specific character might determine the number of ways in which we can construe the others. This is because one character's behavior and personality may be categorized as a stimulus capable of prompting reactions in the rest. Which means that in speaking about Othello, Bradley is sometimes indirectly speaking about Iago. This is an aspect of Bradley's discourse which also accounts for its consistency and persuasive power. CTCA may shed some light over this interconnecting aspect of character construing; but let us hear Bradley's argument first:

[Trusting Iago] was no sign of stupidity in Othello. For his opinion of Iago was the opinion of practically everyone who knew him: and that opinion was that Iago was before all things 'honest,' his very faults those of excess in honesty. This being so, even if Othello had not been trustful and simple, it would have been quite unnatural in him to be unmoved by the warnings of so honest a 
friend, warnings offered with extreme reluctance [ . . . Any husband would have been troubled by them. . . (192)

Bradley subtly puts us at a singular crossroads: either Iago is a superb schemer or Othello is stupid. In denying the hero's stupidity, the professor collaterally defends, again, the greatness of Iago. The quoted paragraph is built upon causal reasoning:

[1] ... his opinion of Iago was the opinion of practically everyone who knew him. . .

Othello was not the only one deceived by Iago, which means that Iago's tendency to deceive ranks low in distinctiveness. Iago deceives everybody whatever they do. Therefore, Othello's particular actions - including the promoting of Cassio - are not as necessary to understand Iago's deceiving as a reference to the villain's own dispositions.

[2] . . . if Othello had not been trustful and simple, it would have been quite unnatural in him. . .

Othello's trust in Iago is also presented as low in distinctiveness; someone's naturalness is actually another way of referring to someone's low distinctiveness in regard to certain behaviors and certain stimuli. Othello is such a trustful man that distrust of Iago would have required explanation by referring to external pressure.

[3] ... his opinion of Iago was the opinion of practically everyone who knew him. . . Any husband would have been troubled. . .

References to consensus help protect the General from a possible accusation of stupidity. I think that, somehow, no-one who knows the story's outcome can reasonably doubt that Othello has acted quite obtusely in trusting Iago, but this obtuseness, or stupidity if you like, would have been caused by external pressures and not by internal dispositions in the hero, according to Bradley. So, it is not that Othello is stupid or pathologically jealous, nor both things at the same time; the point for Bradley is that Iago is an exceptional creature. On the surface, Bradley seems to be discussing Othello's character, but everything is causally interconnected in his argument, and by proposing that Othello falls into the trap as anybody would - high consensus - Bradley strengthens his already-discussed theory, to be defended later, of Iago as a grand villain.

It is important to point out that CTCA reasoning does not exclude the possibility of two interconnected behaviors, displayed by two characters, where two attributions to subject coexist as the most plausible explanation for both. There might be ways to construct the situation where Iago's abil- 
ity might coexist with Othello's jealousy, and even Othello's prudence and capabilities might not exclude his obtuseness. I guess that such a description would be more to Leavis's liking. Othello might be construed as a man with an exceptionally strong disposition to jealousy; this jealousy would be elicited by much less than Iago's plotting; and once activated, Othello's jealousy would sink the hero, as some passions do, into exceptional obtuseness, turning him - tragically - into Iago's puppet.

At the same time, Iago can be exceptional in many ways, among them, in detecting someone else's Achilles' heel, and showing extraordinary accuracy and slyness at shooting his arrows; Othello, having been hit where he is most vulnerable, might remain the memorable epitome of selfdestructing jealousy, reaching summits of obtuseness, vehemence and aggressiveness which no-one else would come close to - i.e. low consensus and possible attribution to subject.

\subsection{Attenuating circumstances and qualifying attributions}

Up to now I have been treating CTCA reasoning as if observers always had to choose one of three attributions - to stimulus, circumstances or subject - automatically excluding any possible interference of the other two. However, CTCA may allow for mixed categories, where circumstances or stimulus or subject may not necessarily constitute the one and only variable to fully explain behavior. Going back to the exam example, we might easily find a situation where a high consensus shows that the exam was difficult and, at the same time, a bad cold made it impossible for the subject to perform at her best. This means high consensus together with low consistency, a combination which does not lead to any of the three pure attributions we have been discussing so far.

We can find something of this in Bradley's discussion. Even when a clear disposition towards evil can be found both in Iago and Shakespeare's Richard III, the first one stands out and triggers our disgust much more than the second, because as Bradley points out concerning Richard: "his physical deformity, separating him from other men, seems to offer some excuse for his egoism" (205), and also "he is the representative of his family" (205). So, social marginalization and family responsibilities could explain some of Richard's actions, and the more these circumstances manage to explain concerning the tyrant's behavior, the less we will see of his egoistic aureole. In doing this, Bradley qualifies the attribution to subject that explains Richard's behavior, although he does so, again, in order to defend the purity of an attribution to subject in the case of Iago.

In construing Othello, Bradley's strategy consists in emphasizing the hero's nobility and goodness - internal attributions - and then using 
external attributions to undermine rival readings. As we have already seen, his pivotal defense of the General against stupidity and jealousy rests on an attribution to stimulus. Circumstances also play a role here as I am about to show. This is Bradley's consideration of the role of the hero's race within the plot:

I do not mean that Othello's race is a matter of no account. It has, as we shall presently see, its importance in the play. It makes a difference to the action and catastrophe. But in regard to the essentials of his character it is not important; and if anyone had told Shakespeare that no Englishman would have acted like the Moor, and had congratulated him on the accuracy of his racial psychology, I am sure he would have laughed. (187)

Some readers of this paper might be surprised at the insinuation that race is circumstantial, since it is a permanent feature of one's physiognomy. Obviously, a subject's permanent physiognomical features play no causal role in her behavior. But when these physiognomical features constitute a stimulus to which other people react - especially with prejudice and marginalization - such reactions do constitute an external factor which may easily influence the subject's behavior. Race is circumstantial in the context of foreignness and social prejudice.

The fact that Othello is a Moor among Italians, an African among Europeans, a black among whites has, according to Bradley, a certain influence on the plot; it is, actually, an extenuating circumstance that Bradley adds to the list of reasons to demonstrate that Othello is not characteristically jealous: "he is not an Italian, nor even a European" and therefore "he is totally ignorant of the thoughts and the customary morality of Venetian women" (193). Once more, Bradley takes us away from Othello, who is merely a victim caught in an artful trap, and Iago comes to the front:

To represent that Venetian women do not regard adultery so seriously as Othello does, and again that Othello would be wise to accept the situation like an Italian husband, is one of Iago's most artful and most maddening devices. (193, footnote)

Iago's condition of being Italian has no causal impact on the plot according to Bradley: "With [Shakespeare] differences of period, race, nationality, and locality have little bearing on the inward character" (210). It is only on the surface that this statement contradicts the previous one in regard to the importance of Othello's race. Iago's italianity is not associated with foreignness or marginalization. Quite healthily - if I may say so - Bradley refuses to establish any permanent connections between races or nationalities, on one hand, and internal dispositions on the other; he does not establish such connections because, he thinks, Shakespeare would 
not do so either. Iago's dispositions have nothing to do with his being Italian, just as Othello's dispositions have nothing to do with the color of his skin.

Actually, it is quite obvious to me that those who would congratulate Shakespeare for faithfully depicting the psychology of blacks or Moors would be indulging in prejudice. In CTCA terms, they fail to distinguish between internal and external causes of behavior. ${ }^{11}$ Strictly speaking, foreignness - and not race - is a plausible cause of Othello's loss of confidence, which eventually may lead, together with other circumstances and stimuli, to disproportionate behavior.

There is also here, buried in Bradley's argumentation, a perception of high consensus. When Bradley suggests that Shakespeare would laugh if someone told him that "no Englishman would have acted like the Moor", he is also letting high consensus, again, settle the matter: Moors, Englishmen, Italians, Europeans, Caucasians ... anybody would have succumbed to Iago's plotting and to the effects of cultural alienation. The social effects of race may qualify the action, and open the way to empathy and sympathy, but they do not fully explain it.

I do not want to close this section without considering the effects of attributions to circumstances in literary narratives. A villain like Richard III may well behave the way he does mainly because of his inner dispositions, but, at the same time, certain circumstances might favor such behavior and contribute to increasing their disproportional nature. In the case of Othello, also the circumstance of being foreign and culturally alienated may partly qualify the vehemence of his acts. In literature as in life, extenuating circumstances have the property of stimulating the observer's ability to sympathize and empathize. Therefore, if attributions to subject make characters special, interesting, sometimes terrible but always memorable, attributions to circumstances may qualify our perception of them, promoting identification and opening further paths of enjoyment. If attributions to subject tend to deify characters, then attributions to circumstances tend to humanize them. It is obvious that both play an essential role in literary characterization.

\section{CTCA and literary critical practice}

\subsection{Implicit theories of causality}

At this point, I think I have already presented enough evidence relating to the possible ways in which CTCA might help us bring the humanizing approach to fictional characters to a higher level of methodological sensitivity. Still, I have learned through experience that the conscientious 
application of CTCA to the analysis of characters has a certain entropic potential. It is necessary to examine as closely as we can the cognitive ground upon which CTCA stands. Notice, for instance, that up to now, notions like stimulus, circumstance and disposition have been used as primitives. However, a closer look will show them as abstract, open and fuzzy categories used in the subjective organization of raw data.

Before applying CTCA logic, interpretation and categorization have to take place. It is each observer's business to decide which piece of perception will count as stimulus, and which as circumstance; it is the observer who has or does not have knowledge about the consistency and distinctiveness of the subject's reactions. Once the pertinent interpretative decisions have been made, as long as the subjective principles have not been infringed, ${ }^{12}$ the result will be endowed with sense, even if other observers prefer their own different versions. This means that the perception of a character can be properly construed and, at the same time, it can be different from another properly construed version.

If observers are to handle the categories of stimulus and circumstance within a matrix of covariance, first it is necessary for them to be able to select pieces of observable data and to confer them the rank of stimulus or circumstance. Therefore, these so called pieces of data must incorporate certain specific characteristics for them to work as manageable categories. I would say that for something to count as stimulus there must preexist the belief that it is causally and habitually connected to certain behaviors more properly called reactions. Being pricked with a needle qualifies better to count as a stimulus than putting on a jacket. A circumstance is any state of affairs which may modify the subject's habitual responses to stimuli. Likewise, some states of affairs seem more readily interpretable as circumstances than others. Having won a lottery, for instance, qualifies more as a circumstance than being waiting for the train. In both cases, it is a habitual connection between general types of events and general types of behaviors what makes it possible to organize perceptions into the categories required by CTCA.

In sum, we can view CTCA reasoning as a process that stands upon an implicit theory of causality, with both personal and cultural elements. Even the implicit theory of personality which supports the process of traitattribution could be considered a part of this theory of causality, since a disposition can only be defined by its property of causing a limited but well defined set of behaviors. ${ }^{13}$ Kelley's theory stands upon a ready-made constellation of assumptions half-consciously accepted by the observer which establish causal connections between events, along the lines of notions such us normality and proportionality. The way I view it, this constellation is open and fuzzy, adaptable and negotiable. 


\subsection{Consensus, projection and relativism}

If determining what counts as stimulus, circumstance and disposition, requires an implicit theory of causality, for determining whether consensus, consistency and distinctiveness are significantly high or low we often indulge in subjective projection. Let us consider for a moment the concept of consensus. Deciding whether a certain behavior is low in consensus would require either a statistic analysis - the percentage of students who failed an exam- or, much more frequently, a subjective move. In everyday interactions, when I decide that someone's reaction is low in consensus I am assuming that very few people would react like her; but this is, after all, just an opinion; as such, it is based on my own personal idea of what a normal and proportionate reaction would have been.

In many cases, the situation is quite unproblematic. A heartrending cry, for instance, is universally felt to be quite a disproportioned response to a light tap on the shoulder. But sometimes some observers might categorize as a significantly anomalous response what others see as absolute normality. We have already discussed instances of disagreement of this kind. Some consider that Iago's plotting is simply a response to professional frustration or jealousy, and they feel no need to look for more. Bradley senses that there is a disproportion between the offence and Iago's response, and therefore turns his attention towards the character's dispositions. But who is right? If we answer that both are, then we have to face the problem of subjectivism. If everything goes, then nothing really goes; this is the path to cognitive impasse, or what I would call terminal relativism.

Discrepancies in the understanding of behavior seem to be further complicated by the subtle intricacies of what psychologists call projection. In its traditional psychoanalytic version, projection is a defensive mechanism by which we read within others' behavior the libidinal and thanatal drives which are actually pressing inside us, but which we do not want to accept. Under this light, any subjective judgment points to the reader rather than to the character. For example, if $\mathrm{I}$, as a reader, defend the notion that Iago is acting out of ambition, this would mean that I am projecting upon the villain my own subconscious conflicts with unaccepted ambitious drives, and I will feel repulsion towards the villain. I would view Iago as a consensual anomaly: 'most people would not respond like him ... I certainly wouldn't!'

Likewise, those who think that Othello's fall is satisfactorily explained by his own jealousy, would be those for whom jealousy is a critical issue, pressing from inside. Those who tend to tolerate jealousy in themselves as something perfectly natural - "any man situated as Othello was would have been disturbed by Iago's communications" - would tend to blame 
Othello's crime on Iago. And so on. There is some truth, I believe, in this oversimplified account of projection in character perception; although it fails in that it considers the reader an automatic interpreting machine, unable of consciously and critically evaluating her own mental processes and updating them whenever necessary. And this is where terminal relativism may be overcome, and where literary criticism regains its ground.

\subsection{Facing terminal relativism}

The fact that we never leave the domain of subjectivity when interpreting the causal structure of plots and characters does not mean that we are necessarily determined by our interpretative mechanisms to a point where no negotiation is possible. Negotiation between different subjectivities is not only possible, it constitutes a natural and general goal in society to the extent that we might consider it unavoidable. Actually, the notions of reader and reading gain in richness, complexity and accuracy when we realize that subjectivity is not necessarily a hermetically closed and rigid domain, but rather a malleable substance ready to be shaped and reshaped according to objectifiable principles. In the words of A. Pilkington:

The mind is guided, on the one hand, by the desire to improve the accuracy of its memory by maximizing cognitive effects. These take the form of the strengthening of already existing beliefs, the weakening or contradiction of already existing beliefs, leading to their rejection, and the calculation of new beliefs from the combination of new and old information. (2000: 73)

How do our beliefs get stronger or weaker? In our search for "a more reliable representation of the world" (Pilkington, 73), how do we develop the sense that our updated representation is more reliable than the old one? I suggest two possible but not mutually exclusive answers. A representation which gains in sophistication and complexity, both in range and depth, will probably be felt as reliable. ${ }^{14}$ Also, a representation which is sufficiently shared by other members of the group, therefore granting smooth and efficient interaction, will also be felt reliable. Bradley's sophisticated Iago is bound to be preferred to the popular and simpler one, provided that it is consensually accepted or acceptable by other readers.

However, the fact that we can read literature for our own private enjoyment means that we can live happily with an unreliable representation of a fictional world as long as we find it pleasurable. ${ }^{15}$ The situation is quite different for literary critics and scholars. In our case, the exigencies derived from our condition as social mediators will constantly force us to try and overcome interpretations based on our own dispositions and our own 
attributional styles (Wiener 474) for the fact that such interpretations cannot be considered satisfactorily reliable and efficient. Our task often consists in obtaining richer and more complex representations of the objects we study, and also in promoting general agreement concerning our views. In regard to plot and character analysis, the habit of monitoring closely and in an orderly way the premises of our causal argumentation - why not guided by theories like CTCA? - would help us go beyond our own dispositions and accept other readings which might be even more enjoyable.

\section{Conclusions}

The basic idea underlying the cognitive approach is that we make sense of reality by projecting over it a series of mental structures. Otherwise, reality would be meaningless. Once our schemas, expectations, scripts, etc. interact with the observed world, its objects bloom with a meaning which seems to come from within themselves.

If we are ready to accept that this is the way we extract sense from the outer world, and we strictly abide by this belief, then Bradley's procedure is just as legitimate as it is effective. He uses his mental structures, his (unchecked) theories of causality and personality, his own personal understanding of social and psychological relations; and he uses all this material in order to make sense of Shakespeare's Iago and Othello.

One would too easily feel entitled to ask Bradley to base his argumentation exclusively on facts provided by the text. In remaining within the limits of the text, we tend to think, our interpretations will be more truthful to the nature of their objects. But Bradley does use facts from the play, as well as assumptions from his imagination. The point is that there is a logical continuity between both sets of data. He assumes, with no other authority than his common sense, that "Iago was ignorant of military science" (212), or that "he was not of gentle birth or breeding" (213), or that "he took his pleasures when and how he chose" (218). There is no doubt that these facts are all invented, but if Bradley had tried to convince us that Iago was an aristocrat, expert on military matters, mentally weak and easily influenced, we would soon see that such a version has much less power to interact productively with the data provided by the play.

Bradley does not invent just any facts, he conjures up those that can be reasonably integrated with the ones provided by the text and that can contribute to make sense of characters. He is not capricious here; he is using his imagination subordinated to his folk-psychological dexterity, in order to convey a maximum of fullness, intelligibility and grandeur to 
Shakespeare's characters. Not that Shakespeare really needs his help, but neither does he need Knights' or Leavis'.

What Bradley does, relying exclusively on his own intuitions and common sense, we can now do with the aid of social psychology. However, the humanizing approach is, and can only be, subjective by definition. As in everyday person perception processes, the construal of fictional characters needs active and even creative participation on the part of the reader. Such creativity is, as we have shown, regulated by principles based on nondemonstrative logic. One of the particularities of this kind of reasoning is that it renders results which are, at the same time, very convincing and easy to refute. Certainly, the involvement of the reader's subjectivity may also allow for the interference of psychological projection. There is no reason to suppose, however, that such projections are to be avoided; in fact, one might argue that we would feel nothing towards fictional characters if we did not project on them our fears and desires, our psychological issues.

What CTCA has to offer is not an infallible access to the ultimate truth of fictional characters, but rather a method for shaping and expressing our intuitions about them, and for arguing effectively in favor of our perceptions. With Kelley's theory I can defend my perception of a character like Iago, and using the same theory, another reader may reasonably refute it. Literature viewed under this light is a meeting point for the negotiation of experience and subjectivity; any literary scholarship that accepts this principle offers us the chance to learn about writers and characters, but also about readers and readings. I would say that in relation to fictional characters truth is not so much a statement as a searching dynamism, not so much a proposition as a practice.

University of Valladolid

\section{Notes}

Correspondence address: ecamara@fyl.uva.es

1. Attribution to subject is also called internal attribution, whereas attributions to stimulus and circumstance may be considered two cases within the more general category of external attribution.

2. According to B. Weiner, "attribution theory is as central to personality psychology as it is to social psychology". He provides an example: "answers to a question such us "Why have I failed" surely can affect self-esteem (consider the consequences of the answer "I am dumb"). In addition self-esteem is likely to influence the answer to the question" (465).

3. A trait attribution theory may understand such behavior as the token of a more general type of behaviors, and may therefore incorporate a predictive value. Since a behavior B' 
is a token of the type B, other behaviors such as B", B", Bn might be expected. This is the kind of informative potential gathered within a personality trait.

4. Weiner speaks of an "intersection of attribution theory and personality psychology" (465).

5. Explaining a trait away actually means substituting it by a state (Weiner, 471-472). The difference has to do with their predictive power. A psychological state "being unstable over time, cannot be predicted from past experience with person, but may be controlled by manipulating the situation" (Chaplin, 555).

6. I will leave the third version for later, because it is presented as an attribution to subject.

7. For most of which there is no direct textual evidence.

8. Going back to Chaplin (555), Othello's jealousy would not be considered a stable trait with predictive potential, but a transitory state, which can only be induced by environmental manipulation.

9. With Shakespeare, character is often destiny (Bradley, 13). Knights resented this premise, because “'character' - like 'plot', 'rhythm', 'construction' [...]- is merely an abstraction from the total response in the mind of the reader" (4). According to Knights, a play by Shakespeare is rather a word-design aimed at communicating a certain valuable experience as whole. Therefore "To stress in the conventional way character or plot or any of the other abstractions that can be made, is to impoverish the total response" (4). On my part, I would think twice before stating that Bradley's experience of Othello is poor or impoverished. Personal, yes; subjective, too; but the great popular success of this kind of approaches, which Knights inconsolably acknowledges, is pointing to a way of enjoying literature which must have an intelligibility to be elucidated by cognitive researchers.

10. The underlying belief here would go as follows: 'those who can plan intricate schemes and complete them successfully have to be very clever and may naturally tend to feel superior to those who are manipulated'.

11. Of course, social psychological discussions of prejudice are lengthy and complex (Hogg, 341-382; Augoustinos, 225-270). It has never been the goal of attribution theories like CTCA to account for such things as prejudice, although, attributing the cause of someone's behavior to her race is a obviously a prejudiced attribution to subject. As Weiner points out, "there are enduring tendencies or inclinations toward particular causal perceptions" (466). An attributional style like prejudice constitutes a trait in the observer. In the following section I will touch on this topic.

12. If I said, for instance, that there is nothing particular in the way a person walks - high consensus - and then I said that his way of walking confirms that he is exceptionally extraverted, I would be infringing CTCA logic.

13. With stimulus and circumstance, we establish a connection between two sets of observable affairs: stimulus and circumstance on the one hand, and behavior on the other. In the case of disposition, we associate a certain observable behavior, with an abstract category. Still, the three categories, stimulus, circumstance and disposition, are perceived as casually connected to behavior, and therefore, it is possible to consider the three of them as elements within a general theory of causality.

14. In my opinion, the construing of Iago as a psychopathic schemer is more sophisticated than the version of the villain as an ambitious or envious man. Therefore I tend to prefer Bradley's view, because it offers me more and fresher cognitive effects.

15. Actually, for private readers who do not care much for literary criticism, reliability in literature might equal enjoyment. 


\section{References}

Augoustinos, M., I. Walker \& N. Donaghue. 2006. Social cognition: An integrated introduction. London: Sage.

Bradley, A. C. 1904. Shakespearean tragedy: Lectures on Hamlet, Othello, King Lear, MacBeth. London: MacMillan.

Chaplin, W. F., O. P. John \& L. R. Goldberg. 1988. Conceptions of traits and states: Dimensional attributes with ideals as prototypes. Journal of Personality and Social Psychology 54. 541-557.

Chatman, S. 1978. Story and discourse: Narrative structure in fiction and film. New York: Cornell University Press.

Culpeper. J. 2001. Language \& characterization: People in plays \& other texts. London: Longman.

Emmott, C. 1997. Narrative comprehension: A discourse perspective. Oxford: Oxford University Press.

Hastie, R. \& N. Pennington. 1989. Notes on the distinction between memory-based versus on-line judgments. In J. N. Bassili (ed.), On-line cognition in person perception, 1-17. Hillsdale: Lawrence Erlbaum.

Hewstone, M., W. Stroebe \& K. Jonas (eds.). 1996. Introduction to social psychology: A European perspective. Oxford: Blackwell.

Hogg, M. A. \& G. M. Vaughan. 2002. Social psychology. London: Pearson Prentice Hall.

Jones, E. E. \& K. E. Davis. 1965. From acts to dispositions: The attribution process in person perception. In L. Berkowitz (ed.), Advances in experimental social psychology, Vol. 2, 219-266. New York: Academic Press.

Kelley, H. H. 1967. Attribution theory in social psychology. In D. Levine (ed.), Nebraska symposium on motivation, 192-240. Lincoln, NE: University of Nebraska Press.

Kelley, H. H. 1973. The processes of causal attribution. American Psychologist 28. 107-128.

Knights, L. C. 1963. Explorations: Essays in criticism mainly on the literature of the seventeenth century. London: Chatto \& Windus.

Pfister, M. 1988. The theory and analysis of drama. Cambridge: Cambridge University Press.

Pilkington. A. 2000. Poetic effects: A relevance theory perspective. Amsterdam: John Benjamins.

Schneider, D. J., A. H. Hastorf \& P. C. Ellsworth. 1979. Person perception. London: Addison-Wesley.

Stewart, R. A., G. E. Powell \& S. J. Chetwynd. 1979. Person perception and stereotyping. Westmead: Saxon House.

Toolan, M. J. 1988. Narrative: A critical linguistic introduction. London: Routledge.

Totton, N. \& M. Jacobs. 2001. Character and personality types. Buckingham: Open University Press.

Wain, J. (ed.). 1971. Shakespeare Othello: A casebook. London: The MacMillan Press.

Weiner, B. 1990. Attribution in personality psychology. In L. A. Pervin (ed.), Handbook of personality: Theory and research, 465-485. New York: The Guilford Press. 